\title{
CONSCIÊNCIAS LITERÁRIAS DA CRISE: LITERATURA EM TEMPOS DE TURBULÊNCIA SOCIAL
}

\author{
Leomir Cardoso Hilário* \\ Universidade do Estado do Rio de Janeiro
}

\begin{abstract}
Resumo: Este artigo sugere a noção de "consciências literárias da crise", isto é, formas de consciências opositoras em tempos de crises do capitalismo que se expressam por meio de obras literárias, marcadas por uma profunda negatividade em relação ao presente. Estas formas de consciência são engajadas na dupla tarefa de descrever os efeitos de barbárie provocados pelas crises e também de narrar as mudanças ocorridas na sociedade e nos modos de vida dos indivíduos. Além disso, seriam carregadas de energia utópica, de tal maneira que a negação do mundo vigente abre espaço para a possibilidade de outro mundo. Com esta noção, pretendo reafirmar, no quadro histórico atual marcado pela crise estrutural, a especificidade, potencialidade e relevância da literatura para a produção de uma crítica radical do presente. Retomo as obras de Franz Kafka, Aldous Huxley e Samuel Beckett, alinhando-as com períodos históricos distintos: A Era da Catástrofe, a Era de Ouro e o Desmoronamento, respectivamente.
\end{abstract}

Palavras-chave: Teoria Crítica. Literatura. Crise. Barbárie. Utopia.

E nos olhos dos homens reflete-se o fracasso. E nos olhos dos esfomeados cresce a ira. Na alma do povo, as vinhas da ira diluem-se e espraiam-se com ímpeto, crescem com ímpeto para a vindima. (STEINBECK, 1979, p. 173).

O objetivo mais amplo deste texto é situar a literatura como uma modalidade de consciência social em tempos de crise. A intenção é evidenciar a importância da literatura no entendimento do período histórico atual caracterizado por uma regressão profunda. Para compreensão dos impactos de determinados contextos históricos, sociais e políticos nas vidas dos indivíduos, é comum que o acadêmico contemporâneo busque suas fontes em obras de sociologia, filosofia, ciência política, psicologia social etc. É inegável que estes saberes produziram diversos e importantes efeitos de análise. No entanto, entendo que a literatura tem

Esta obra está licenciada sob uma Creative Commons - Atribuição 4.0

\footnotetext{
Doutor em Psicologia Social pela Universidade do Estado do Rio de Janeiro. E-mail: leomirhilario@yahoo.com.br.
} 
uma especificidade que a torna extremamente potente e singular, a saber, a capacidade de atravessar a miríade de discursos científicos, políticos e sociais.

Num país periférico como o Brasil, a literatura oscilou entre "assumir a tarefa de participar da construção de uma nova identidade nacional" e "apreciar em profundidade o sentido e os efeitos da modernização dos costumes materiais e espirituais" (RONCARI, 2003, p. 97). Se tomarmos como exemplo a passagem da sociedade colonial para a sociedade produtora de mercadorias, veremos como a literatura foi capaz de captar a forma especificamente periférica e brasileira deste trânsito.

É certo que autores como Sérgio Buarque de Holanda (1995) e Caio Prado Jr. (2011) demonstraram, cada um a seu modo, as consequências desta passagem, tanto na esfera cultural (o homem cordial) quanto na esfera histórico-econômica (o sentido da colonização). No entanto, antes, já em Machado de Assis havia reflexões sobre o estranho traço brasileiro de amalgamar arcaico e moderno, vide as reflexões de Roberto Schwarz (1997), que o considerou como "um mestre na periferia do capitalismo". Também já em Manuel Antônio de Almeida existiam reflexões profícuas sobre o modo de ser dos brasileiros livres na ordem escravocrata, o que levou o crítico literário brasileiro Antonio Candido (2015) a falar de uma "dialética da malandragem" a partir de Memórias de um sargento de milícias.

Da mesma maneira que na filosofia, na sociologia e na psicologia, também na literatura brasileira podemos traçar perspectivas distintas e antagônicas. Por exemplo, ainda de acordo com Luiz Roncari (2003), de um lado teríamos a perspectiva ideológica que correspondia às aspirações da política dominante, cujo objetivo era afirmar a então nova simbologia nacional; de outro lado teríamos a perspectiva crítica, cujo compromisso é com os efeitos da modernização, com os novos modos de vida. Assim como naqueles saberes, esta divisão não é uma marca intransponível, onde se está de um lado ou de outro definitivamente. Assim como Karl Marx, do ponto de vista da sociologia, - sempre oscilando entre uma leitura dialética e uma positivista, com um pé na modernidade e outro fora dela, como atestam seus trechos mais radicais e suas leituras mais reducionistas - também nomes como José de Alencar e Gonçalves Dias oscilaram entre promover o indianismo como afirmação de uma identidade nacional e encontrar um novo modo de fazer literatura.

Isto significa que os escritores brasileiros não puderam saltar para fora da imposição do processo de produção de valor na periferia. Por meio da literatura, tematizaram o que nós podemos ser diante da modernização e o que a modernização faz conosco. Talvez este tenha sido um dos motivos que levaram alguns escritores que focalizaram o Nordeste brasileiro e 
suas tradições a se vincularem ao Partido Comunista Brasileiro, como Jorge Amado, Graciliano Ramos e Raquel de Queiroz. De um lado, então, o caldo tradicional cultural brasileiro nordestino e de outro a organização modernizadora por excelência.

A literatura, além de transversalizar saberes e colocar para si a tarefa de pensar um determinado tempo histórico ${ }^{1}$, também possui uma relação íntima com a utopia. Ao descrever e problematizar o mundo no qual ela se inscreve, a literatura não tem a intenção da neutralidade axiológica do saber nem o compromisso com a predição e controle dos acontecimentos - dois pressupostos/dogmas do saber científico moderno. Distante disso, a literatura é como fragmentos de um outro mundo. Sua particularidade aparece como a recusa de permanecer idêntica a este mundo, portanto.

Mesmo quando este cientificismo adentrou na literatura, como nas descrições exaustivas de um Émile Zola ou de um Aloísio de Azevedo, isto foi feito não em nome da ciência neutra, mas sim a serviço de um conjunto de movimentos e intenções de ruptura social. Como uma torção irônica, na literatura, o chamado Naturalismo (a corrente mais cientificista do Realismo), adotou o método da descrição do mundo exatamente como ele se apresentava e a conduta do escritor como um cientista social que analisa a realidade como maneiras de a literatura encontrar a sua denúncia enquanto mundo horroroso, explorador e desigual $^{2}$.

\section{II}

$\mathrm{Na}$ interpretação do filósofo húngaro Georg Lukács (2010, p. 156), haveria dois modos de representação artística na literatura moderna. $\mathrm{O}$ primeiro poderia ser chamado de arte de narrar. Seu contexto seria o da ascensão do capitalismo por meio de suas crises cíclicas, os "múltiplos e tortuosos caminhos que conduzem da velha sociedade em decomposição à nova que está surgindo". Exemplos desta arte de narrar estariam em Honoré de Balzac, Stendhal, Charles Dickens e León Tolstói. O segundo modo de representação poderia ser chamado de a arte de descrever, própria de um contexto da sociedade burguesa

\footnotetext{
${ }^{1}$ Não raro o leitor ou a leitora de algum romance de Machado de Assis ou Fiódor Dostoiévski estará defronte a discussões filosóficas e políticas profundas iniciadas por uma conversa em um bar ou num jantar. Dada a condição periférica do Brasil e da Rússia, coube à literatura a tarefa que, em outros países centrais, foi legada à filosofia, isto é, a de pensar o mundo, de fornecer um diagnóstico do presente. Esta é uma das razões pelas quais há tanta filosofia nestes dois romancistas.

2 Se nos lembrarmos da consolidação da psicologia social enquanto disciplina científica na Grã-Bretanha (ÁLVARO; GARRIDO, 2006), quando Herbert Spencer assumiu o ponto de vista de Charles Darwin para além da evolução biológica, compreendendo-a como aplicável a todos os aspectos da realidade, veremos claramente a distância entre ciência e literatura: na primeira, a adoção dos pressupostos positivistas deu lugar a um movimento conservador no interior da psicologia (e também da sociologia, vide o darwinismo social), na segunda, ao contrário, a ciência é revirada ao avesso, a literatura faz a mudança social passar por dentro dela.
}

Anu. Lit., Florianópolis, v. 22, n. 1, p. 99-115, 2017. ISSNe 2175-7917 
madura, cristalizada e constituída, sobretudo no período pós-1848. Descrever é registrar. O centro do romance descritivo são as coisas e não as pessoas. Lembremos destes títulos: $O$ Cortiço, de Alóísio de Azevedo ou A taberna, de Émile Zola. O homem aparece como produto acabado, o nível poético da vida decai. Apesar da ênfase nas coisas é injusto imputar a estes escritores aquele julgamento que comumente se faz a Émile Durkheim ${ }^{3}$, ou seja, de que seu pressuposto de enxergar os fatos sociais enquanto coisas o leva a privilegiar um ponto de vista segundo o qual a sociedade é regida por leis naturais independentes da vontade humana e, assim, conceber que a sociedade pode ser assimilada epistemologicamente como a natureza, de tal modo que as ciências sociais, como as naturais, devem-se limitar à observação e explicação causal dos fenômenos, de forma objetiva, neutra e livre de julgamentos de valor por parte do cientista social. Por exemplo, ainda que sejam o sobrado e o cortiço os protagonistas do romance de Aloísio de Azevedo, eles carregam em si história e luta: a oposição entre ambos significa a oposição histórica das classes sociais. Enquanto na sociologia, este teor positivista fez sair de cena a transformação social, na literatura seu efeito foi o de injetar ainda mais a necessidade de ruptura.

Desta maneira, narrar é participar, é distinguir e ordenar, é uma ação que decorre sobre algo que já aconteceu. Descrever é algo do presente, descreve-se, portanto, algo que já está ali. Escritores como Gustave Flaubert, Émile Zola e Aloísio de Azevedo, recusam a realidade consolidada da forma social capitalista, opõem-se a ela, exprimem seu horror e desprezo ao regime político e social de seu tempo. Descrevem, portanto, o seu mundo cruel. Tiveram a solidão como destino e tornaram-se observadores e críticos da sociedade burguesa. Já nomes como León Tolstói tomaram parte em guerras que ensejaram transformações profundas na sociedade moderna. Ele visitou o anarquista Joseph Proudhon durante a escrita de seu romance Guerra e Paz, além de ter sido citado pelo anarquista russo Piotr Kropoktin como expoente do "anarquismo cristão".

\footnotetext{
A alternativa participar ou observar corresponde, assim, a duas posições socialmente necessárias, assumidas pelos escritores em dois períodos sucessivos do capitalismo. A alternativa entre narrar ou descrever corresponde aos dois métodos fundamentais de representação próprios destes dois períodos (LUKÁCS, 2010, p. 157).
}

Estas duas formas distintas de representar a realidade histórica da totalidade concreta capitalista indicam determinada necessidade social de um estilo. Georg Lukács já havia proposto isto em seu livro A teoria do romance, no qual ele opôs a epopeia ao romance. A

\footnotetext{
${ }^{3}$ Refiro-me a primeira regra das Regras do Método Sociológico, de Émile Durkheim. Estou seguindo aqui a leitura de Michael Löwy (2000) sobre o positivismo nas ciências sociais.
}

Anu. Lit., Florianópolis, v. 22, n. 1, p. 99-115, 2017. ISSNe 2175-7917 
primeira seria própria de uma totalidade fechada, um mundo perfeito e acabado, onde as respostas existem antes das perguntas, isto é, está tudo de certa maneira escrito nas linhas tortuosas do desenrolar dos acontecimentos. Exemplo mais acabado aqui são as aventuras de Ulisses em seu retorno à Ítaca. Já o romance é a epopeia de uma totalidade cindida e fragmentada, cujo sentido escapa aos protagonistas. Ele é a “epopeia de uma era para a qual a totalidade extensiva da vida não é mais dada de modo evidente, para a qual a imanência à vida tornou-se problemática, mas que ainda assim tem a intenção a totalidade" (LUKÁCS, 2009, p. $55)$.

O herói da epopeia está sempre seguro de quem é, do que deve fazer e para onde deve ir. Ulisses, rei de Ítaca, sabe que deve retornar à sua terra depois da Guerra de Tróia, reencontrar sua amada. Utilizando sua racionalidade consegue enganar deuses, negociar com eles e assim garantir seu retorno. O destino do herói da epopeia é o destino de uma comunidade. O herói do romance moderno é quase o avesso disso. Está jogado num mundo que não compreende, devendo retirar de si mesmo alguma racionalidade que lhe permita agir. Não é este o conflito maior de Raskólnikov em Crime e Castigo? Ou seja, uma vez que a religião se via em crise no alvorecer da sociedade burguesa, por que ele deveria seguir o mandamento "não matarás"? Por que uma velha usurária deveria viver, se a sua morte poderia significar diretamente o melhoramento de sua vida e de sua família? Os personagens dostoievskianos estão abandonados, desamparados: "o processo segundo o qual foi concebida a forma interna do romance é a peregrinação do indivíduo problemático rumo a si mesmo, o caminho desde o opaco cativeiro da realidade simplesmente existente, em si heterogênea e vazia de sentido para o indivíduo, rumo ao claro autoconhecimento" (LUKÁCS, 2003, p. 82). $\mathrm{Ou}$, em uma palavra: "a forma do romance, como nenhuma outra, é uma expressão do desabrigo transcendental" (LUKÁCS, 2003, p. 38).

O que me interessa aqui nestes argumentos de Georg Lukács é este balizamento da literatura com a sociedade a partir da história, i. e., como a literatura assume formas específicas de expressão a partir de sua relação com determinado contexto social e histórico. O seu pressuposto de que "o verdadeiramente social da literatura é a forma" (LUKÁCS, 1992, p. 174) deve ser encarado como um ponto de partida metodológico.

Como argumentei anteriormente ${ }^{4}$, a literatura é uma das fontes principais de conhecimento da Escola de Frankfurt, como é mais conhecida. Walter Benjamin aprendeu muito com Charles Baudelaire, assim como Theodor Adorno com Samuel Beckett, Herbert

\footnotetext{
${ }^{4}$ Cf. HILÁRIO, 2013, p. 201-215.
} 
Marcuse com George Orwell e assim por diante. Para esta tradição do pensamento crítico, a literatura não se resume a um saber ilustrativo, mas a um campo específico de reflexão acerca do mundo histórico no qual ela se inscreve. A literatura, portanto, assim como a filosofia, a sociologia, a psicologia e a história, por exemplo, permite compreender quais são as forças que constituem o presente, quais são as mudanças que estão ocorrendo nos modos de vida, quais tipos de sofrimento emergem a partir de tais mudanças etc. Por meio da literatura, portanto, é possível compreender a sociedade.

O que chamo de "consciências literárias da crise" são formas de consciência emergidas em contextos de crises do capitalismo. Mais do que isso, são formas de consciência opositoras, carregadas de negatividade em relação ao presente. Sua dupla tarefa é denunciar/descrever os efeitos de barbárie provocados pela crise ao mesmo tempo em que aponta/narra para a possibilidade de viver de outra maneira. Num momento histórico em que a psicologia adere mais e mais aos ditames de uma disciplina científica integrada ao capitalismo, em que a sociologia perde sua capacidade crítica por meio de um colonialismo cultural, em que a filosofia abandona a negatividade analítica, é preciso encontrar outro espaço onde a crítica radical seja possível. Esse caminho foi trilhado por nomes como Karl Marx, que já não fez mais sociologia nem filosofia, mas sim crítica da economia política; como Sigmund Freud, que já não fez mais psicologia nem psiquiatria, mas sim metapsicologia ou psicanálise; como Friedrich Nietzsche, que talvez tenha feito mais genealogia do que filosofia e assim por diante.

Em tempos de crise como os atuais, é urgente que encontremos espaços onde a crítica possa caminhar sem tantos constrangimentos e eu penso que a literatura constitui ainda um desses espaços, dada sua irredutibilidade a outro saber e sua recusa em participar da departamentalização do conhecimento. A literatura é um reduto de não-identidade, para falar como Theodor Adorno (2009), quer dizer, na literatura encontramos lugar e potência de um mundo que não se reduz ao existente, de uma realidade que não se extingue no atual, de fragmentos de futuro na paralisia do presente. Para demonstrar isto, passo a analisar muito resumidamente as obras de Franz Kafka (A Metamorfose), Aldous Huxley (Admirável Mundo Novo) e Samuel Beckett (Fim de Partida). São escritores cujas obras constituem verdadeiros testemunhos das forças que compõem o mundo do qual ainda somos prisioneiros.

Vou emparelhar Kafka, Huxley e Beckett aos três momentos que constituem o que Hobsbawm (1995) chamou de "curto século XX". Em seu clássico livro chamado A Era dos Extremos, ele defende que existiram três eras no interior do último século: a primeira seria a 
Era da Catástrofe, situada entre 1914 e 1945, marcada pelo colapso da civilização do século XIX, por duas guerras mundiais, pela Grande Depressão e a emergência do stalinismo, fascismo e nazismo; a segunda seria a Era de Ouro, entre 1945 e 1973, caracterizada pelo crescimento econômico aliado com ampliação de direitos sociais e políticos em diversos países da Europa, mas também por aquilo que Herbert Marcuse (2015) ironicamente chamou não de Welfare State mas sim de Warfare State; a última seria o que ele chama de Desmoronamento ou Décadas de crise, caracterizada sobretudo por uma dinâmica de crise que deixou de ser episódica e passou a ser um processo histórico de longa duração, pelo aparecimento do desemprego estrutural em massa, pelo colapso do sistema mundial e hegemonia neoliberal.

Assim, vou traçar paralelos entre: a) Kafka e a Era da Catástrofe, no sentido de um contexto no qual o valor se expande a todo o vapor, absorvendo mais e mais força de trabalho, reduzindo homens e mulheres a peças de engrenagem do modo de produção de mercadorias. A meu ver, nele podemos encontrar uma modalidade de consciência literária que consiste em pôr as crises como catástrofes naturais, isto é, acontecimentos que não conseguimos prever nem compreender, tal é o grau de alienação desta forma social; b) Aldous Huxley e a Era de Ouro. No meu entender, Huxley narra as mudanças ocorridas na sociedade que encontrou sua forma consolidada de funcionamento, que dirimiu a oposição e migra seus exercícios de dominação para o interior dos indivíduos. Esta forma de consciência literária entende a crise como contexto histórico-cultural de intensificação dos efeitos de dominação social; c) por fim, Samuel Beckett e o Desmoronamento, isto é, parece-me que a forma de consciência literária de Beckett põe a crise enquanto processo de dissolução social que carrega a natureza, a sociedade e os indivíduos em seu desfazimento.

A partir destes emparelhamentos da literatura, sociedade e história, entendo que é possível resgatar o potencial analítico da literatura, ou seja, sua capacidade de produzir efeitos de análise sobre as crises sociais. Em tempos de crise estrutural como os atuais, a literatura pode fornecer um lugar de reflexão e crítica, de problematização e recusa daquilo que nos tornamos.

\section{III}

\section{Franz, Kafka e a expansão do fetichismo da mercadoria}

Prima facie, os romances kafkianos são incompreensíveis. Em um, o protagonista se vê processado por algo que desconhece; em outro, está jogado num espaço cujas coordenadas de compreensão lhe escapam; e, no mais conhecido, seu protagonista se vê metamorfoseado 
num inseto gigante ao acordar. Quem se aventura a abrir um de seus livros, logo perceberá seu método, que é desloucar a aparência normal de nosso mundo para tornar visível sua loucura constitutiva. A partir daí, como observou Günther Anders (2007), ele manipula essa aparência louca como algo normal. Ou, como disse Modesto Carone (2009), o método kafkiano consiste em colidir a linguagem tipicamente cartorial, de protocolo, com o inverossímil da coisa narrada:

Quando certa manhã Gregor Samsa acordou de sonhos intranquilos, encontrou-se
em sua cama metamorfoseado num inseto monstruoso. Estava deitado sobre suas
costas duras como couraça, e, ao levantar um pouco a cabeça, viu seu ventre
abaulado, marrom, dividido por nervuras arqueadas, no topo do qual a coberta,
prestes a deslizar de vez, ainda mais se sustinha. Suas numerosas pernas,
lastimavelmente finas em comparação com o volume do resto do corpo, tremulavam
desamparadas diante de seus olhos (KAFKA, 2011, p. 227)

Engana-se o leitor e a leitora que considerar que essa estranheza narrada de maneira tão natural se encerra neste primeiro parágrafo. Isso constitui todo o romance. Nos parágrafos seguintes, o protagonista estará mais preocupado em não perder a hora de seu trabalho do que com a condição estranha de seu corpo. A isso, Gunther Anders chamou de "princípio da explosão negativa", ou seja, o fato de que o espantoso, em Kafka, é que o espantoso não espanta ninguém. Diante de um acontecimento explosivo e incompreensível, o mundo simplesmente conserva inalterada a intensidade do som, como se tudo continuasse como sempre foi.

O contexto histórico de Franz Kafka, do início do século XX, é o contexto de expansão do capitalismo, onde seu modo de produção se expande para várias partes do globo. O que se dissemina não são somente a corrente elétrica, as ferrovias, as estradas, os carros etc., mas também o que Karl Marx chamou de "fetichismo da mercadoria". A sociedade burguesa é uma forma social alienada, construída cotidianamente por seus membros que, apesar disso, dela não têm controle imediato. Assim, os produtos de sua ação, as mercadorias, aparecem para ele como coisas que lhe permitem realizar sua sociabilidade. Neste quadro, os homens e mulheres não conseguem comida porque a produzem, mas sim porque, a partir dos produtos de seus trabalhos, adquirem o meio necessário (dinheiro) para adquirir comida.

As práticas sociais no capitalismo não são diretas, mas intermediadas pelos produtos do trabalho, que se autonomizam diante do produtor. Os laços sociais se estabelecem, então, por meio da mercadoria, dotada agora de um poder social invertido, já que priva o indivíduo de sua essência (a sociabilidade), sendo ela mesma aquilo que garante a conexão social. Ocorre, então, o estabelecimento de relações reificadas entre as pessoas e relações sociais 
entre coisas:

\begin{abstract}
Aqui, os produtos do cérebro humano parecem dotados de vida própria, figuras autônomas, que mantêm relações entre si e com os homens. Assim, no mundo das mercadorias, acontece com os produtos da mão humana. Isso eu chamo de fetichismo que adere aos produtos de trabalho, tão logo são produzidos como mercadorias, e que, por isso, é inseparável da produção de mercadorias (MARX, 1983, p. 71).
\end{abstract}

Os indivíduos realizam sua sociabilidade por meio de coisas, isto é, sua existência apenas se efetiva por meio da troca de mercadorias: a compra de objetos para necessidades básicas vem pela troca determinado tempo de trabalho. São os produtos de seu trabalho que lhe dão o estatuto de ser sociável. Dito de outra maneira: os indivíduos, na sociedade produtora de mercadorias, são privados de sua qualidade de ser social, e apenas podem recuperá-la por meio de coisas (mercadorias/produtos de seu trabalho). O que há aqui é determinada forma inconsciente de relação social.

Nesta perspectiva, as pessoas são agentes de um processo social que lhes é alheio, pois as mercadorias não vão por si só ao mercado nem saem andando das prateleiras. Elas “não o sabem, mas o fazem" (MARX, 1983, p. 72). Melhor ainda: elas, as pessoas, não precisam saber ou ainda que saibam não deixarão de fazer. Com este conceito, Marx caracteriza o capitalismo como um sistema que não se reduz ao domínio de uma classe sobre outra, mas como uma determinada sociedade dominada por abstrações reais e anônimas.

Num mundo em que o saber não importa muito e em que a dominação abstrata incompreensível se impõe, o narrador kafkiano aparece como princípio formal de construção do romance desta época. As crises sociais aparecem, então, como verdadeiros acontecimentos catastróficos semelhantes a desastres naturais, isto é, como eventos nunca previstos e cuja ocorrência é incompreendida. Trata-se daquilo que Georg Lukács chamou de "segunda natureza":

Pois, de um lado, os homens quebram, dissolvem e abandonam constantemente os elos "naturais", irracionais e "efetivos", mas, por outro e ao mesmo tempo, erguem em torno de si, nessa realidade criada por eles mesmos, "produzidas por eles mesmos", uma espécie de segunda natureza, cujo desdobramento se lhes opõe com a mesma regularidade impiedosa que os faziam outrora os poderes irracionais. (LUKÁCS, 2003 p. 272)

Na primeira natureza, em última análise, o destino da humanidade está para além de seu próprio controle, de modo que acontecimentos como as catástrofes naturais não podem ser exatamente previstas e/ou controladas. Na segunda natureza, este poder alheio à vontade dos indivíduos assume nova feição, uma vez que produtos de sua própria ação (como guerras e 
crises econômicas, por exemplo) assumem também o caráter de natural, incompreensível, incontrolável: "seu próprio movimento social assume para eles a forma de um movimento de coisas que os controla em vez de ser controlado por eles" (MARX, 1983, p. 100). O fetichismo da mercadoria não é algo que se limita à esfera da produção material de mercadorias, mas algo que faz parte da totalidade das relações sociais da sociedade moderna.

O narrador kafkiano parece ser a "consciência literária do fetichismo da mercadoria", pois torna compreensível porque as crises aparecem para nós como acontecimentos repentinos sem conexão conosco. Lembremos do último crash de 2008 nos Estados Unidos, onde todos foram pegos de surpresa com o estouro da bolha imobiliária que levou consigo gigantes bancos e deixou um rastro de barbárie social, com pessoas sendo despejadas de suas casas. Mas não precisamos ir tão longe, lembremos da queda rápida do governo petista depois de pouco mais de uma década de calmaria econômica e política brasileira.

A crise aparece, então, não como aquilo que põe em jogo a existência deste sistema, como um testemunho de que a sua dinâmica de reprodução deve ser questionada, mas sim como um tsunami incompreensível que nos atinge de tempos em tempos. A "consciência literária da crise" kafkiana denuncia o caráter alienante de nossas relações sociais, o modo pelo qual perdemos a capacidade de nos indignar diante dos efeitos de barbárie provocados pela crise e como perdemos a potência criativa e imaginativa de fazer com que nosso pensamento ultrapasse a imediaticidade desse mundo.

\section{IV}

\section{Aldous Huxley ou quando o poder adentra os indivíduos}

A denúncia desta totalidade fetichista do capitalismo está também no escritor inglês Aldous Huxley. Anos depois de ter escrito Admirável Mundo Novo, ele afirmou que

[...] forças impessoais as quais quase não podemos controlar parecem estar a empurrar-nos a todos em direção ao pesadelo descrito no Admirável Mundo Novo; e este impulso impessoal está sendo cuidadosamente acelerado por representantes de organizações comerciais e políticas que desenvolveram um número avultado de notas técnicas de manipulação em prol dos interesses de uma minoria, dos pensamentos e sentimentos das massas. (HUXLEY, 1959, p. 19)

Aquela alienação social, que aparece em Kafka como princípio de ordenamento do mundo, ganha contornos mais internos em Huxley. Ou seja, a alienação aqui não somente aquilo que circunda o indivíduo, reduzindo-o a peça de engrenagem do modo de produção capitalista e acabando com sua humanidade, mas também aquilo que o constitui. É como se a alienação adentrasse os indivíduos. Na linguagem de Michel Foucault, por exemplo, é como 
se as relações de poder adentrassem os indivíduos ${ }^{5}$. Ou, para lembrar de Giorgio Agamben (2010), uma conjuntura histórica marcada pela politização da vida biológica. Ambos problematizam a entrada da vida da espécie humana na ordem do saber, do poder e das técnicas políticas, em outras palavras, o momento histórico em que o homem é posto como animal cuja vida está permanentemente colocada como questão política.

A meu ver, há uma volta no parafuso da dominação fetichista se compararmos Kafka e Huxley. Se Gregor Samsa se via como gigante inseto incapaz de trabalhar, Huxley considera a possibilidade de que a sociedade capitalista produza medicamentos eficazes para contornar esta situação, tanto no sentido de fazer com que a percepção corporal volte ao "normal" quanto recuperar a capacidade produtiva de Gregor. Ou seja, "o princípio da produção em série aplicado enfim à biologia" (HUXLEY, 2003, p. 14).

A "forma de consciência literária" de Aldous Huxley nos chama a atenção para o fato de que as crises sociais podem levar todos nós juntos com ela, isto é, fazer sumir nossa autonomia e nossos corpos. Ela não somente nos torna estranhos ao mundo, mas também, por outra via, cria mecanismos pelos quais este estranhamento suma. Ou seja, a sociedade pode nos identificar a esta forma social, de tal maneira que não exista mais ponto de fuga, que tenha sumido do mapa a não-identidade, a diferença entre sujeito e objeto, indivíduo e sociedade etc.

A partir desta forma específica de consciência literária da crise, podemos compreender por que num mundo em que não há trabalho para todos e há trabalho para cada vez menos pessoas, é comum que se submeta a períodos de trabalho ainda mais brutais a base de medicamentos que buscam eliminar o stress e o enfado mental. Ou, ainda, como surge uma ideologia do empreendedorismo, com suas técnicas de pensamento que devem ser integradas ao modo de pensar dos indivíduos como uma via de conseguir sucesso - mindset, atitude mental para o sucesso, no vocabulário de Carol S. Dweck.

Não vejo distância entre a noção de "tecnologia humana" de Nikolas Rose e esta crítica literária social de Aldous Huxley, pois ambas querem chamar atenção para um conjunto dinamizado por uma racionalidade prática governada por uma meta específica. Em outras palavras, estas tecnologias humanas aparecem como "agregados híbridos de saberes, instrumentos, pessoas, sistemas de julgamento, construções e espaços, sustentados no nível programático por certos pressupostos e objetivos concernentes aos seres humanos" (ROSE, 2011, p. 45). Neste prisma, a escola e a prisão podem ser consideradas tecnologias humanas

\footnotetext{
${ }^{5}$ Refiro-me à frase: “as relações de poder penetram os corpos” (FOUCAULT, 1994, p. 228).
} 
cujo objetivo é produzir o sujeito politicamente dócil e produtivamente útil.

Com Huxley, é possível então afirmar este intento de produzir subjetividade e não somente reduzir a subjetividade e os corpos como em Kafka. São fases distintas do capitalismo: Kafka está escrevendo no contexto do capitalismo a pleno vapor, cuja característica principal é a mobilização total e intensa da força de trabalho. A imagem emblemática desta época é a cena de Tempos Modernos, onde Chaplin se encontra em meio a uma grande máquina, como sendo parte da engrenagem, ou aquela na qual o protagonista, depois de executar tantos movimentos repetitivos, sai da fábrica tentando aparafusar até botões de roupas. Aldous Huxley, por outro lado, apesar de escrever em 1931, narra a sociedade capitalista consolidada, não mais ancorada naquilo que Karl Marx (1983) chamou de mais-valor absoluto, mas sim no mais-valor relativo, ou seja, no aumento de produtividade por outros meios que não a extensão do tempo, mas sim por meio de constantes inovações técnicas, ou seja, quando o capitalismo produz matérias de acordo com sua necessidade de valorização do valor (vide as inovações de Taylor e Ford, como a esteira mecânica, um objeto cujo objetivo é a produção de mais mercadorias em menos tempo de trabalho). A exploração migra do corpo para a mente, a estranheza física e corporal dá lugar à alienação mental e psíquica.

\section{V \\ Samuel Beckett e a estética da vida mercantil esgotada}

Se Franz Kafka pode ser colocado como o narrador da época da expansão do fetichismo da mercadoria e Aldous Huxley como o narrador da consolidação do modo de produção capitalista, Samuel Beckett é o narrador da época da dissolução e declínio da sociedade burguesa. No primeiro, a consciência literária da crise denunciava o modo pelo qual o dinamismo social escapou do controle dos indivíduos, de tal maneira que as crises se apresentavam então como catástrofes naturais, imprevisíveis e incompreensíveis. No segundo, a consciência literária da crise aparecia como denúncia da migração do poder social para o interior dos indivíduos, de tal modo que as crises são vistas como momentos de agudização dos exercícios de poder, numa dinâmica de barbárie que pode extinguir as possibilidades de se viver de outra maneira.

A “forma de consciência literária da crise" em Beckett é a que traduz as ruínas da sociedade capitalista. Em outras palavras: se o romance é a forma estética da experiência de viver na sociedade burguesa, Beckett é a forma literária da vida em declínio que caracteriza o atual momento histórico. Sigo a interpretação de Robson José Feitosa de Oliveira: 
A forma do teatro de Beckett expressa a forma-sujeito burguesa não mais em desenvolvimento, não mais entrecruzada e carregando o peso de formas de subjetividade anteriores. Ela é uma alegoria da realização plena da vida social burguesa e seu sujeito no auge, um auge que culmina com sua crise de dessubstancialização. Portanto, o teatro de Beckett não é apenas um teatro da crise do sujeito moderno, mas um teatro em que crise e realização se confundem. Porque no teatro de Beckett a crise não é devida a um defeito, a uma impropriedade, a um desajuste superável, mas ao fato de uma irracionalidade ter alcançado seu mais alto nível de perfeição. (OLIVEIRA, 2016, p. 268)

Obra de 1954, Fim de partida retrata personagens que são "portadores dos despojos da civilização burguesa, dos restos do otimismo da razão iluminista, convertidos em bugiganga" e que estão "às voltas com a tarefa de acabar de existir, virtualmente infinita e de conclusão impossível" (ANDRADE, 2010, p. 14). Vivem, então, num contexto de um mundo que já não mais se sustenta em pé, cujo dinamismo não garante mais sua reprodução. Em outras palavras: vivem numa quadra histórica onde a sociedade burguesa já não está mais em ascensão nem em consolidação, mas em colapso.

Esta dinâmica histórica se caracteriza pelo fato de a forma social capitalista já não integra mais seus membros por meio da exploração massiva da força de trabalho, mas sim os desintegra e os descartabiliza. O modo de produção capitalista, em seu estágio de colapso, cria incessantemente massas supérfluas, formadas por pessoas que já não são mais requeridas ao processo de produção, cuja capacidade de trabalhar já não faz mais diferença ao modo de produção de mercadorias.

"Meu assunto é o fracasso", teria dito certa feita Samuel Beckett. Mas, no século XXI, poderíamos acrescentar: o problema contemporâneo refere-se ao fracasso/esgotamento desta sociedade, sua incapacidade de produzir civilização. Estamos, portanto, às voltas com o fracasso histórico de uma forma social específica. Houve uma passagem da lógica da produção/distribuição de riqueza material para a lógica de produção/distribuição de riscos, destruição e barbárie (BECK, 2011). Trata-se aqui não de uma racionalidade a plenos pulmões imprimindo sua dinâmica fetichista e alienante para a totalidade concreta, também não se trata de uma racionalidade que adentrou a subjetividade de seus membros, mas de uma racionalidade em frangalhos, que já não consegue mais entregar aquilo que promete, que se vê reduzida a sua dimensão bárbara e destrutiva:

HAMM - E o horizonte? Nada no horizonte?

CLOV (abaixando a luneta, volta-se para Hamm, exasperado) - Que você esperava que houvesse no horizonte?

Pausa.

HAMM - As ondas, como estão as ondas?

CLOV - As ondas? (Direciona a luneta) De chumbo.

HAMM - E o sol?

CLOV (ainda olhando) - Zero. 
HAMM - Deveria estar se pondo. Procure bem.

CLOV (depois de procurar) - Dane-se o sol.

HAMM - Então já está escuro?

CLOV (olhando) - Não.

HAMM - Está o quê, então?

CLOV (olhando) - Cinza (Abaixando a luneta e voltando-se para Hamm, mais alto)

Cinza! (Pausa. Mais alto ainda) CIINZA! (BECKETT, 2010, p. 71-72).

É possível ver neste tipo de atmosfera estética alguma coisa diretamente conectada ao mundo da Segunda Guerra Mundial. Contudo, penso não ser forçoso entendê-la a partir da atual quadra histórica do século XXI. Esta passagem dá a impressão de que já não há mais natureza. Como disse Theodor Adorno (2003, p. 274): "A fase de completa reificação do mundo no qual já não há nada que não tenha sido feito pelos homens, é indistinguível de um sucesso catastrófico suplementarmente provocado exclusivamente por homens, no qual a natureza foi anulada e depois nada mais cresce".

A barbárie enquanto processo objetivo e histórico de destruição do mundo é como um espiral que carrega consigo as formas de subjetividade: "o contexto das peças de Beckett é, portanto, de um mundo em que a natureza já não é mais natureza, é terra arrasada" (OLIVEIRA, 2016, p. 275). Robson Oliveira resumiu muito bem a frase de Hamm - "o fim está no começo e no entanto continua-se" (BECKETT, 2010, p. 113) - ao dizer que "o fim de tudo está começando, mas seguimos em frente". Esta experiência de fim de mundo, de viver numa forma social claramente declinante, é uma das marcas de nosso tempo histórico atual.

A "consciência literária da crise" beckettiana, no meu entender, põe a crise como acontecimento característico de uma forma social em ruínas, isto é, a crise seria como o desfazimento da totalidade concreta, um desmoronamento que arrasta a tudo e todos, reduzindo-nos não a meras peças de engrenagem nem a elementos funcionais de uma ordem em pleno funcionamento, mas sim a estilhaços de barbárie, peças disfuncionais entregues à própria sorte e à própria insignificância, cuja força de trabalho se tornou supérflua e cuja capacidade de resistência foi anulada.

\section{VI \\ Da necessidade da utopia}

Seria ainda possível falar em utopias nestas três formas de consciência literária da crise? Não estaríamos jogados, em Kafka, Huxley e Beckett, num universo sem escapatória, como alguém que olha uma luz vinda do fim do túnel e, aos poucos, dá-se conta de que se trata de um trem vindo em sua direção? Estes escritores seriam manifestações literárias daquelas aporias insolúveis ou becos sem saída que se meteram intelectuais como Max 
Horkheimer, Theodor Adorno e Herbert Marcuse ${ }^{6}$ ?

Para quebrar esta impressão de que estes escritores são derrotistas e pessimistas, vale lembrar que Franz Kafka participou de reuniões de grupos anarquistas, Aldous Huxley se empenhou em discussões públicas em torno da política e democracia, e Samuel Beckett participou da Resistência Francesa na época da Segunda Guerra Mundial. O alto teor de negatividade em suas obras literárias tem mais a ver com um certo tipo de papel a ser desempenhado pela literatura em tempos de turbulência social. O que quero dizer é que por meio do alto grau de negatividade exposto em suas obras literárias, estes escritores põem em xeque a existência dessa forma social, demonstram os efeitos de barbárie que ocorrem e ocorrerão se tudo permanecer igual como está. Porém isso não significa que eles abandonaram o campo de batalha. De alguma maneira, seguiram aquela máxima de Max Horkheimer (1973, p. 70) de ser "pessimista teórico e otimista prático".

Talvez eles deixem uma lição a nós que temos a tarefa histórica de resgatar uma crítica radical do presente aliada com um horizonte emancipatório: a de pintar o mundo sem ceder à chantagem de estarmos carregando a tinta em demasia nos mecanismos de poder e de destruição desta sociedade. Porque o lastro de uma crítica radical é exatamente ali onde a irracionalidade dessa forma social se faz presente de maneira mais brutal. Como disse Kafka: se há esperança, é unicamente em nome dos desesperançados, em nome daqueles para os quais não há futuro, nem sequer presente. A utopia para o nosso tempo é uma utopia negativa (LÖWY, 2005), nascida a partir da impossibilidade de que as coisas continuem da maneira que estão.

\section{Referências}

ADORNO, Theodor W. A dialética negativa. Rio de Janeiro: Jorge Zahar, 2009. . Intento de entender Fin de partida. In.: . Notas sobre literatura. Madrid: Akal Ediciones, 2003, p. 270-310.

AGAMBEN, Giorgio. Homo Sacer: o poder soberano e a vida nua. Belo Horizonte: Editora UFMG, 2010.

ÁlVArO, José L.; GARRIDO, Alicia. Psicologia Social - perspectivas psicológicas e sociológicas. São Paulo: McGraw-Hill, 2006.

\footnotetext{
${ }^{6}$ Esta é a acusação de Jürgen Habermas com a qual não concordo, embora entenda que é uma leitura a ser levada em consideração, porque vale mais como questão levantada do que resposta encontrada. Investiguei isso melhor em: A potência da crítica: o problema da aporia em Habermas e seu destino em Adorno. Revista Kriterion, Belo Horizonte, v. 55, n. 129, p. 309-329, jun. 2014.
} 
ANDRADE, Fábio de Sousa. Matando o tempo: o impasse e a espera. In.: BECKETT, Samuel. Fim de partida. São Paulo: Cosac Naify, 2010, p. 7-31.

ANDERS, Günther. Kafka: pró e contra. São Paulo: Cosac Naify, 2007.

BECK, Ulrich. A sociedade do risco: rumo a uma outra modernidade. São Paulo: Ed. 34, 2011.

BECKETT, Samuel. Fim de partida. São Paulo: Cosac Naify, 2010.

CANDIDO, Antonio. Dialética da Malandragem. In.: . O Discurso e a Cidade. Rio de Janeiro: Ouro sobre azul, 2015, p. 17-47.

CARONE, Modesto. Lição de Kafka. São Paulo: Companhia das Letras, 2009.

FOUCAULT, Michel. Les rapports de pouvoir passent à l'intérieur des corps. In.:

Dits et écrits. Tomo 3. Paris: Gallimard, 1994, p. 228-236.

HILÁRIO, Leomir C. Teoria Crítica e Literatura: a distopia como ferramenta de análise radical da modernidade. Anuário de Literatura, Florianópolis, v. 18, n. 2, p. 201-215, 2013.

HOBSBAWM, Eric. A Era dos Extremos: o breve século XX (1914-1991). São Paulo: Cia das Letras, 1995.

HOLANDA, Sergio Buarque de. Raízes do Brasil. Rio de Janeiro: Cia das Letras, 1995.

HORKHEIMER, Max. Sociedad en transición: estudios de filosofía social. Barcelona: Planeta-Agostini, 1973.

HUXLEY, Aldous. Admirável Mundo Novo. São Paulo: Editora Globo, 2003. . Regresso ao Admirável Mundo Novo. São Paulo: HEMUS, 1959.

KAFKA, Franz. A metamorfose. In.: Classics Companhia das Letras, 2011, p. 227-247. Essencial Franz Kafka. São Paulo: Penguin

LÖWY, Michael. As aventuras de Karl Marx contra o Barão de Münchhausen: marxismo e positivismo na filosofia do conhecimento. São Paulo: Cortez, 2000.

. Franz Kafka: sonhador insubmisso. Rio de Janeiro: Azougue editorial, 2005.

LUKÁCS, Georg. A teoria do romance. São Paulo: Ed. 34, 2009.

. História e Consciência de Classe: Estudos sobre a dialética marxista. São Paulo: Martins Fontes, 2003.

Narrar ou descrever? In.: Marxismo e Teoria da Literatura. São Paulo: Expressão Popular, 2010, p. 149-185.

. Reflexões sobre a sociologia da literatura. In: 1992, p. 173-188. . Sociologia. São Paulo: Ática, 
MARCUSE, Herbert. $O$ homem unidimensional: estudos da ideologia da sociedade industrial avançada. São Paulo: EDIPRO, 2015.

MARX, Karl. O capital: crítica da economia política: Livro I: o processo de produção do capital. São Paulo: Abril Cultural, 1983.

OLIVEIRA, Robson José Feitosa de. O homem sem qualidades à espera de Godot: Molière, Musil, Beckett, Macunaíma e o devir vazio tautológico na modernidade. 2016. 308 f. Tese (Doutorado em Psicologia Social) - Universidade do Estado do Rio de Janeiro, 2016.

PRADO JR., Caio. Formação do Brasil Contemporâneo. São Paulo: Cia das Letras, 2011.

RONCARI, Luiz. Esboço para o estudo do ponto de vista da mercadoria na literatura brasileira. Crítica Marxista, Campinas, n. 17, p. 96-108, nov. 2003.

ROSE, Nikolas. Inventando nossos selfs: psicologia, poder subjetividade. Petrópolis: Vozes, 2011.

SCHWARZ, Roberto. Um mestre na periferia do capitalismo. Machado de Assis. São Paulo: Ed. 34, 1997.

STEINBECK, John. As vinhas da ira. São Paulo: Abril Cultural, 1979.

\section{Literary consciences of the crisis: literature in times of social turbulence}

Abstract: This paper suggests the notion of "literary consciences of the crisis", i.e., forms of opposite consciences in times of capitalist crises that express themselves by means of literary works, marked by a profound negativity in relation to the present. These forms of consciences are engaged in the dual task of describing the effects of barbarism settled by the crisis and also of narrating the changes that occurred in the society and the ways of life of individuals. Furthermore, they would be charged with utopian energy, in such a way that the negation of the present world opens space to the possibility of another world. With this notion, I intend to reaffirm the specificity, in the historical present characterized by structural crisis, potentiality and relevance of literature to the construction of a radical critique of present time. I return to the works of Franz Kafka, Aldous Huxley and Samuel Beckett, aligning them with distinct historical periods: The Age of Catastrophe, the Golden Age and the Fall, respectively.

Keyword: Critical Theory. Literature. Crisis. Barbarism. Utopia.

Recebido: $29 / 12 / 2016$

Aceito: 05/05/2017

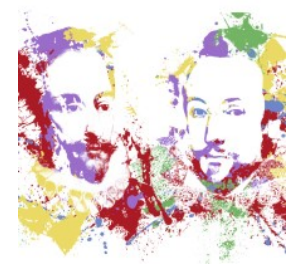

